\title{
Effects and Regulation of Connective Tissue Growth Factor on Hepatic Stellate Cells
}

\author{
Valerie Paradis, Delphine Dargere, Franck Bonvoust, Michel Vidaud, \\ Patricia Segarini, and Pierre Bedossa
}

Service d'Anatomie Pathologique (VP, PB), Hôpital de Bicêtre, Le Kremlin-Bicêtre, and CNRS UPRES-A8067 (VP, $D D, F B, P B)$ and Laboratoire de Génétique Moléculaire JE 2195 (MV), Faculté de Pharmacie, Paris V, France; and

Fibrogen (PS), San Francisco, California

\begin{abstract}
SUMMARY: Connective tissue growth factor (CTGF) is a 38-kd protein involved in several human fibrotic disorders including atherosclerosis and skin and renal fibrosis. Although it has been shown that human and experimental liver fibrosis is associated with CTGF expression through up-regulation of CTGF mRNA by hepatic stellate cells (HSC), the role of CTGF in the liver has not yet been determined. The aim of the present study was to assess the effects of CTGF on rat primary HSC and its regulation in a well-established model of in vitro liver fibrogenesis. Incubation of primary HSC with recombinant CTGF induced a significant migratory (2.3-fold, $50 \mathrm{ng} / \mathrm{ml} \mathrm{CTGF)} \mathrm{and} \mathrm{proliferative} \mathrm{effect} \mathrm{(1.8-fold,} 100 \mathrm{ng} / \mathrm{ml}$ CTGF). Type I collagen mRNA expression, as assessed by a real-time RT-PCR procedure, was also increased when cells were incubated in the presence of CTGF (2-fold, 50 $\mathrm{ng} / \mathrm{ml})$. Transforming growth factor- $\beta 1$ (TGF- $\beta 1$ ) strongly stimulated CTGF mRNA expression, a direct mechanism observed in the absence of any intermediate protein synthesis. Furthermore, spontaneous activation of HSC plated on plastic and stimulation by vascular endothelial growth factor, lipid peroxidation products (HNE, MDA), acetaldehyde, and platelet-derived growth factor (PDGF)-BB significantly up-regulated CTGF mRNA expression in HSC. PDGF-induced CTGF stimulation might be related in part to TGF- $\beta 1$ secretion because CTGF mRNA up-regulation observed after PDGF-BB stimulation was abrogated in the presence of neutralizing TGF- $\beta 1$ antibody. In conclusion, this study extends the role of CTGF in HSC activation and suggests that CTGF up-regulation might be a central pathway during HSC activation. (Lab Invest 2002, 82:767-773).
\end{abstract}

iver fibrosis, the hallmark of chronic liver diseases,
is a dynamic process involving mainly hepatic stellate cells (HSC) and a large nümber of mediators, with a special role for transforming growth factor- $\beta$ (TGF- $\beta$ ) (Nakatsukasa et al, 1990; Pinzani et al, 1989; Weiner et al, 1990). Connective tissue growth factor (CTGF) is a 38-kd protein, originally isolated from supernatants of human vascular endothelial cells, that promotes differentiation, proliferation, and migration of different types of cells (Bradham et al, 1991). Several studies have shown that CTGF is also involved in the fibrogenic process. Indeed, CTGF mRNA expression is up-regulated in numerous human fibrotic disorders including atherosclerosis, skin, and renal fibrosis (Igarashi et al, 1996; Ito et al, 1998; Oemar et al, 1997). In vitro, CTGF stimulates extracellular matrix (ECM) production by fibrogenic competent cells such as fibroblasts and mesangial cells (Frazier et al, 1996; Ito et al, 1998). CTGF biologic activity is partly mediated by the action of TGF- $\beta$. Indeed, CTGF mRNA is

\section{DOI: 10.1097/01.LAB.0000017365.18894.D3}

Received February 4, 2002.

This study was supported by grants from Association pour la Recherche contre le cancer (Grant 9012) and Fond de Recherche de la Sociéte Nationale Française de Gastroentérologie.

Address reprint requests to: Dr. Valérie Paradis, Service d'Anatomie Pathologique, Hôpital de Bicêtre, 78, rue du Général Leclerc, 94275 Le Kremlin-Bicêtre,France.E-mail: vparadis@teaser.fr specifically induced to significant levels in human skin fibroblasts by TGF- $\beta 1$ stimulation (Igarashi et al, 1993; Soma and Grotendorst, 1989). Lastly, a TGF- $\beta-$ responsive element was identified in the CTGF promoter, which may explain the molecular basis for the selective up-regulation of this gene by TGF- $\beta$ (Grotendorst et al, 1996). All these data suggest that CTGF may be a downstream effector of TGF- $\beta 1$ specifically involved in the fibrogenic effect of this growth factor. In a previous work, we showed that CTGF was up-regulated in liver fibrosis both in carbon tetrachloride-induced liver fibrosis in rats and in human chronic liver diseases (Paradis et al, 1999). In this study, CTGF expression was significantly associated with the score of fibrosis in biopsy specimens of chronic hepatitis, and both CTGF immunostaining and in situ hybridization identified HSC as the main source of CTGF. In vitro, increased expression of CTGF was also demonstrated in HSC during its activation process (Paradis et al, 1999; Williams et al, 2000). Although the expression of CTGF has been clearly demonstrated in liver fibrosis, its functional effects and regulation have only been partly investigated. To address this issue, we examined CTGF expression in rat primary HSC during spontaneous activation and various conditions of stimulation that are known to be associated with liver fibrogenesis. To gain further insight into the potential involvement of CTGF in the process of liver fibrosis, we also investigated CTGF 
biologic activities in vitro on HSC, in terms of proliferation, migration, and ECM gene expression.

\section{Results}

\section{Spontaneous Activation of HSC Induces CTGF Up-Regulation}

Spontaneous activation of HSC cultured for several days on plastic is a well-established model of liver fibrogenesis. To investigate CTGF regulation during this process, CTGF mRNA levels was quantified in lysate of primary HSC after 3 days (quiescent state), 5 days (intermediate state), and 7 days (activated state) of culture after plating. Between Day 3 and Day 7, a mean 9-fold increase in CTGF mRNA levels was observed. In parallel, type I collagen mRNA was quantified. As expected, a significant but delayed increase (12-fold) was observed in type I collagen mRNA expression (Fig. 1). This delayed increase of collagen gene suggests a regulatory role of CTGF on collagen gene expression.

\section{CTGF Induces Collagen Gene Expression in HSC}

To confirm the role of CTGF in ECM gene expression, we investigated the direct effect of recombinant CTGF (rCTGF) at various concentrations $(10,50$, and 100 $\mathrm{ng} / \mathrm{ml}$ ) for 16 and 48 hours on type I collagen transcription in quiescent HSC. No significant increase in CTGF mRNA was found for 16 hours of incubation whatever the concentration tested. However, a significant increase was observed when cells were incu-

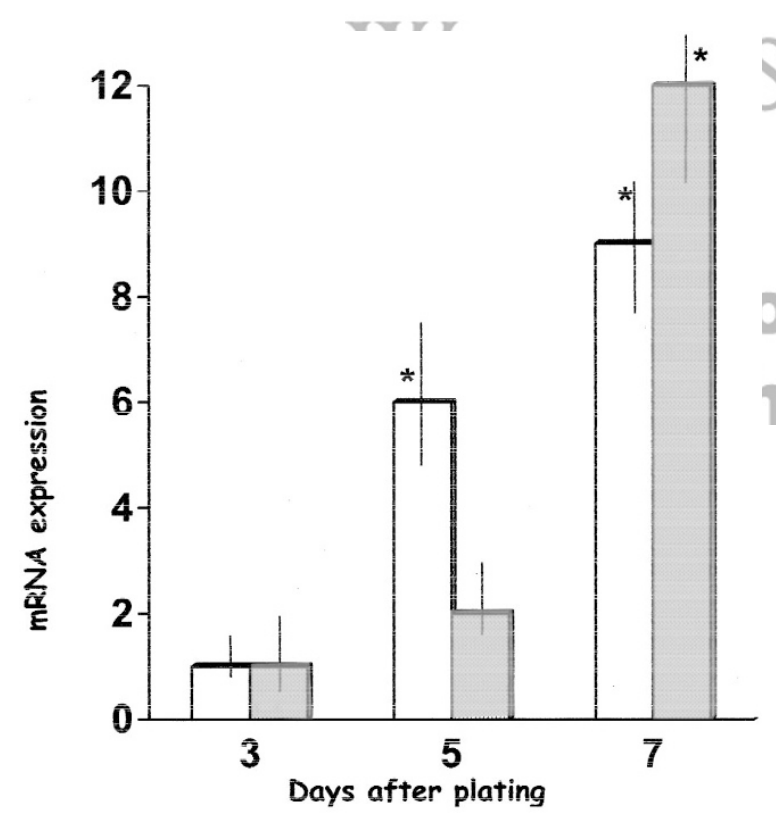

Figure 1.

Connective tissue growth factor (CTGF) and type I collagen mRNA quantification in hepatic stellate cells (HSC) during spontaneous activation in culture. CTGF (white bar) and type I collagen mRNAs (hatched bar) were quantified by real-time RT-PCR in HSC incubated for 3, 5, and 7 days after isolation. The mRNA level at Day 3 was arbitrarily defined as 1 unit. Data are expressed as means \pm SD of three independent experiments $\left({ }^{*} p<0.05\right.$ compared with the control condition). bated for 48 hours in the presence of 50 or $100 \mathrm{ng} / \mathrm{ml}$ of CTGF compared with controls $(2 \pm 0.3$-fold with 50 $\mathrm{ng} / \mathrm{ml}, p<0.05$; Fig. 2). This delayed expression of collagen after CTGF stimulation is in accord with results of the previous experiment. Similarly, a CTGF mRNA up-regulation was observed after rCTGF stimulation, suggesting an autocrine loop of CTGF stimulation (1.8 \pm 0.4 -fold increase, $50 \mathrm{ng} / \mathrm{ml}$ for 48 hours, $p<0.05)$.

\section{TGF- 11 Induces CTGF Up-Regulation in HSC at Both the mRNA and Protein Level}

Because TGF- $\beta 1$ is the major profibrogenic cytokine in the liver and because previous studies showed a role for TGF- $\beta 1$ in CTGF up-regulation, we investigated its potential role in the stimulation of CTGF expression in HSC. To address this issue, CTGF mRNAs were quantified in untreated cells and in cells treated with recombinant TGF- $\beta 1$ at Day 4 after isolation. Among the various concentrations of TGF- $\beta 1$ tested $(0.1,1,5$, and $10 \mathrm{ng} / \mathrm{ml})$, the highest increase was obtained with $10 \mathrm{ng} / \mathrm{ml}$. Under TGF- $\beta 1$ stimulation (10 $\mathrm{ng} / \mathrm{ml}$ for 4 hours), a maximal 4 -fold increase in the CTGF mRNA level was observed. To determine the kinetics of CTGF expression under TGF- $\beta 1$ stimulation, HSC were treated for varying time periods with $10 \mathrm{ng} / \mathrm{ml}$ TGF- $\beta 1$. As shown in Figure 3, the expression increased as early as 1 hour (2-fold, $p<0.05$ ), before reaching a threshold at 4 hours (4-fold, $p<$ $0.05)$, and thereafter declined.

TGF- $\beta 1$-induced CTGF expression was also studied at the protein level. Western blot analysis was then performed on cell lysates from untreated and TGF- $\beta 1$ treated $\mathrm{HSC}_{(10} \mathrm{ng} / \mathrm{ml}$ for 4 hours). A significant increase in the specific 38-kd CTGF protein band was observed in the TGF- $\beta 1$-treated cell layer by comparison with untreated control cell cultures (Fig. 4). These data confirm the regulatory role of TGF- $\beta 1$ on CTGF up-regulation in HSC activation.

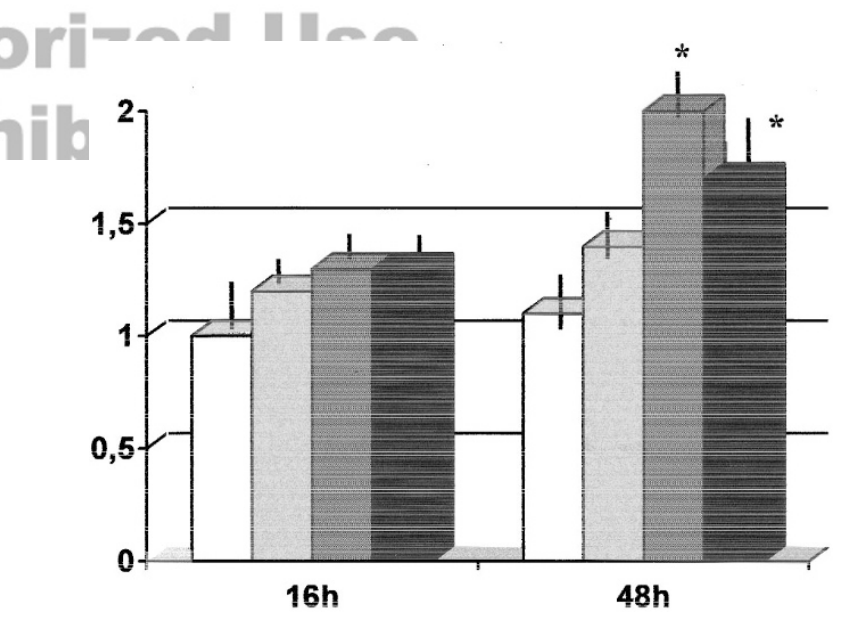

Figure 2.

Effect of recombinant CTGF (rCTGF) on collagen 1 mRNA expression. HSC were incubated in the presence of $10 \mathrm{ng}$ of CTGF (grey bar), $50 \mathrm{ng}$ of CTGF (hatched bar), $100 \mathrm{ng}$ of CTGF (black bar), or without CTGF (white bar) for 16 or 48 hours. Results are mean of three independent experiments. ( ${ }^{*} p<0.05$ compared with the control condition). 


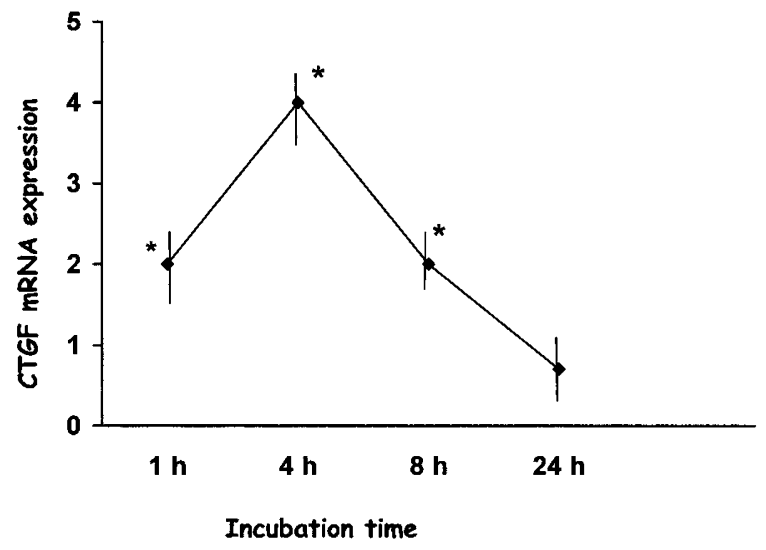

Figure 3.

CTGF mRNA quantification after transforming growth factor- $\beta 1$ (TGF- $\beta 1$ ) stimulation. HSC were incubated in the presence of TGF- $\beta 1(10 \mathrm{ng} / \mathrm{ml})$ for various periods of time $(1,4,8$, and 24 hours). Results are mean of three independent experiments. ( ${ }^{\star} p<0.05$ compared with the control condition). heximide (20 $\mu \mathrm{g} / \mathrm{ml}$ for 30 minutes) before cells were exposed to TGF- $\beta 1$ in optimal conditions of stimulation (10 $\mathrm{ng} / \mathrm{ml}$ for 4 hours). The stimulatory effect of TGF- $\beta 1$ was not blocked by cycloheximide. In fact, cycloheximide slightly increased TGF- $\beta 1$-induced CTGF mRNA expression (1.4-fold). These data show that TGF- $\beta 1$ directly stimulates CTGF gene expression.

\section{Platelet-Derived Growth Factor (PDGF) Induces CTGF Up-Regulation in HSC through TGF- 11 Production}

PDGF is the major mitogenic growth factor for HSC that is up-regulated during HSC activation. To investigate whether PDGF also has a regulatory effect on CTGF expression, HSC were treated at Day 4 after isolation with PDGF at $10 \mathrm{ng} / \mathrm{ml}$ for 4 hours, and CTGF mRNA was quantitated. PDGF induced a mean 1.7fold increase in CTGF mRNA. In this experiment, TGF- $\beta 1$ mRNAs were simultaneously quantitated. Under these conditions, PDGF stimulation induced a 2 -fold increase in TGF- $\beta 1$ mRNA. To assess whether CTGF induction by PDGF was partly related to stimulation by TGF- $\beta 1$, HSC were incubated in the presence of PDGF ( $10 \mathrm{ng} / \mathrm{ml})$ and neutralizing anti-TGF- $\beta 1$ antibody $(25 \mu \mathrm{g} / \mathrm{ml})$. In the presence of neutralizing anti-TGF- $\beta 1$ antibody, the stimulatory effect of PDGF on CTGF production was totally blocked (Fig. 5). This experiment shows that the stimulatory effect of PDGF on CTGF is dependent on the intermediate TGF- $\beta 1$ up-regulation.

\section{Mitogenic and Motogenic Role of CTGF in HSC}

Although fibrogenesis is mainly a result of HSC activation, proliferation and migration are important functions gained by HSC during the activation process and are of major importance for fibrosis to develop. To test the mitogenic function on CTGF, HSC were incubated

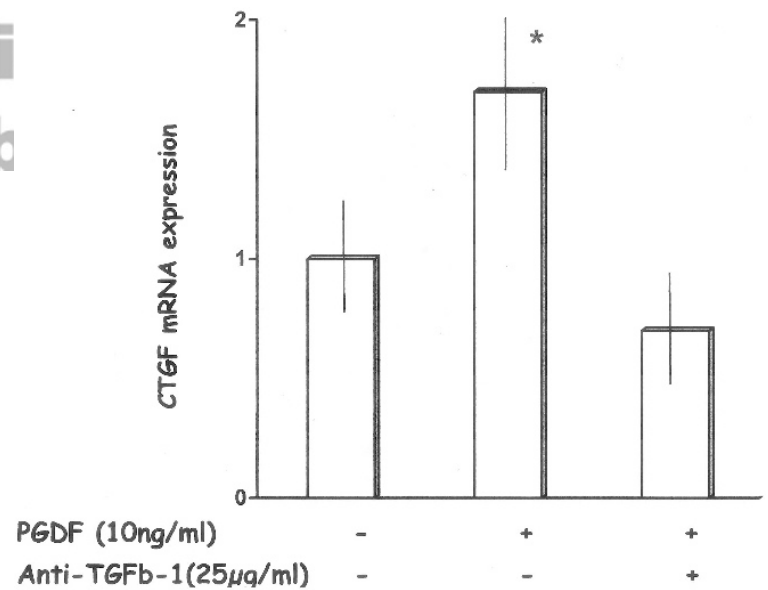

Figure 5.

Stimulation of CTGF mRNA expression by platelet-derived growth factor (PDGF) and effect of neutralizing anti-TGF- $\beta 1$. HSC were incubated in the presence of PDGF (10 ng/ml) for 4 hours. A significant up-regulation of CTGF mRNA was observed. Coincubation with neutralizing anti-TGF- $\beta 1$ antibody (25 $\mu \mathrm{g} / \mathrm{ml}$ ) decreased PDGF-induced CTGF mRNA expression. ( ${ }^{*} p<0.05$ compared with the control condition). regulated by TGF- $\beta 1$ or induced through intermediate protein synthesis, HSC were pretreated with cyclo- 
in the presence of rCTGF. A proliferative response was induced by CTGF as assessed by comparing the incorporation of 5-bromo-2'-deoxyuridine technique (BrdU) in HSC incubated in the absence or presence of rCTGF (50 and $100 \mathrm{ng} / \mathrm{ml}$ ) for 16 hours. A significant increase (1.6-fold) was observed with rCTGF at 100 $\mathrm{ng} / \mathrm{ml}$ compared with control conditions. Data are shown in Figure 6.

To assess the migratory effect of CTGF, primary HSC were seeded in the upper compartment of the modified Boyden chamber and were allowed to migrate through the filter in response to rCTGF. After the addition of PDGF-BB $(20 \mu \mathrm{g} / \mathrm{ml})$, used as positive control, in the lower chamber, HSC migration was increased 2.3-fold as compared with the control (absence of any additional growth factor). In the presence of rCTGF (10, 50, and $500 \mathrm{ng} / \mathrm{ml})$, HSC migration was also increased under all conditions tested (1.3- to 2.3-fold). Data are reported in Figure 7. In addition, when rCTGF was added in the upper compartment, a discrete but not significant increase in HSC migration was also observed (1.1- to 1.3-fold). All these data suggest that CTGF induced migration of HSC both by chemotaxic and chemokinesic effects.

\section{Discussion}

Liver fibrosis is a dynamic process observed in response to various aggressive agents leading, in some cases, to end-stage liver cirrhosis. A key process in this mechanism is HSC activation, by which the fibrocompetent cells of the liver transform into myofibroblasts and gain new functions, such as proliferation, migration, contraction, metalloprotease, and ECM production (Tamatani et al, 1998). Although the mechanisms of increased ECM production and accumulation in the liver have been largely investigated, the involvement of a new growth factor, CTGF, has recently been demonstrated in chronic liver fibrotic

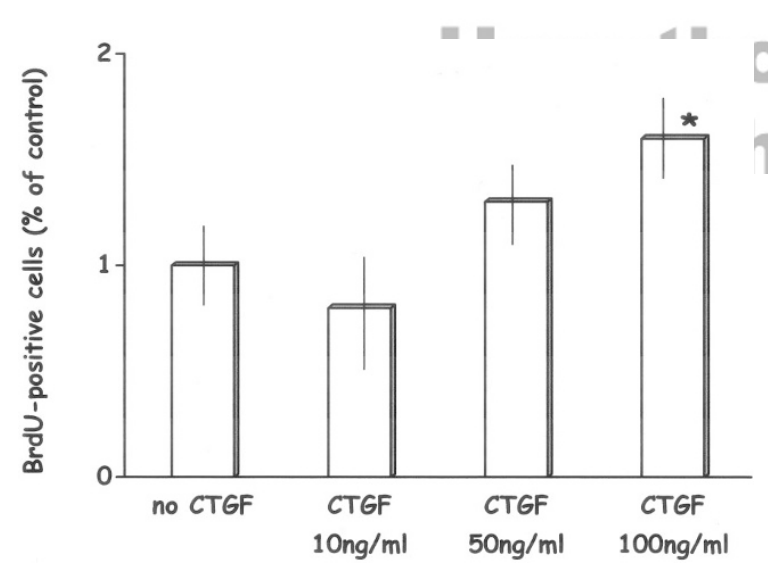

Figure 6.

Effect of CTGF on the proliferation of HSC. HSC were incubated in the presence of $\operatorname{rCTGF}(0,10,50$, and $100 \mathrm{ng} / \mathrm{ml})$ for 16 hours. Cells were labeled with 5-bromo-2'-deoxyuridine technique ( $\mathrm{BrdU})$ for 30 minutes. The number of positive BrdU cells was calculated in 10 random fields at a magnification of $\times 400$ and normalized to the control condition (no CTGF). Data are expressed as means \pm SD of three independent experiments. ( ${ }^{*} p<0.05$ compared with the control condition).

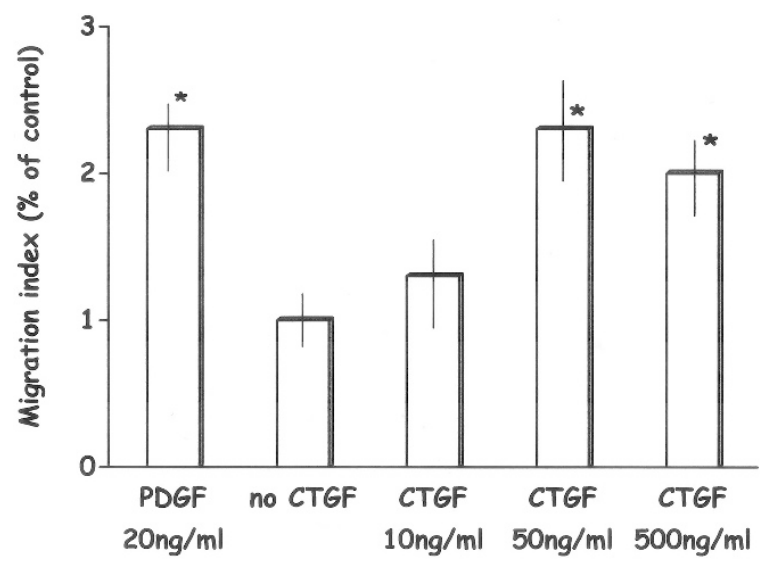

Figure 7.

HSC migration through porous membrane after addition of CTGF. rCTGF was added to the lower compartment of a modified Boyden chamber. The migration index, calculated by counting the ratio of HSC on the lower and upper surfaces of the membrane, was normalized to the control condition (absence of additional growth factor). Results are expressed as means \pm SD of three independent experiments. ( ${ }^{*} p<0.05$ compared with the control condition).

diseases both in humans and animals (Paradis et al, 1999; Sedlaczek et al, 2001; Tamatani et al, 1998; Williams et al, 2000). In the present study, we used the well-established model of HSC culture to gain further insight into the potential role of CTGF in liver fibrogenesis and more generally in HSC activation (Friedman and Roll, 1987). Taken together, our results extend the role of CTGF because CTGF is active not only on ECM gene expression but also on migration and proliferation, two key mechanisms associated with liver fibrogenesis and HSC activation.

Since transformation of freshly isolated HSC toward a myofibroblastic phenotype in vitro resemble the process observed in human liver fibrogenesis, we analyzed CTGF mRNA expression during this spontaneous activation process. Interestingly, CTGF mRNA significantly increased from Day 3 (quiescent HSC) to Day 7 (activated HSC). As expected, we also observed a parallel but delayed increase in type I collagen mRNA, suggesting the close relationships between CTGF up-regulation and ECM production. We then demonstrated a direct effect of rCTGF on collagen gene transcription, supporting the role for CTGF in liver fibrogenesis. Because TGF- $\beta 1$ is the major profibrogenic molecule according to previous reports regarding the close relationship between TGF- $\beta$ and CTGF regulation (Grotendorst et al, 1996), we evaluated the effect of TGF- $\beta 1$ on CTGF expression. As for other mesenchymal cells tested in previous studies, we confirmed a stimulatory effect of TGF- $\beta 1$ (Hong et al, 1999; Ito et al, 2001). Upon TGF- $\beta$ stimulation, a significant increase in CTGF mRNA was observed as early as after 1 hour of incubation; the increase peaked after 4 hours in HSC. Such rapid induction is inconsistent with the involvement of de novo synthesized intermediate proteins between TGF- $\beta 1$ stimulation and CTGF expression. This hypothesis was confirmed because cycloheximide failed to block TGF$\beta 1$-induced CTGF expression. Superinduction of 
CTGF observed under this condition has been attributed to mRNA stabilization related to inhibition of RNA degrading enzymes. It is of note that we showed that not only mRNA but also CTGF protein expression was overexpressed after TGF- $\beta 1$ stimulation. Taken together, these results suggest that CTGF transcription is early and quickly up-regulated during HSC activation, probably via TGF- $\beta 1$ stimulation with, as an end point, ECM production. In this regard, several studies had previously outlined the key role of TGF- $\beta$ and CTGF interaction in tissue fibrosis, including the liver (Hong et al, 1999; Ito et al, 2001; Paradis et al, 1999; Williams et al, 2000).

As previously noted in human foreskin fibroblasts, we observed that PDGF-BB induced a transient increase of CTGF mRNA in HSC. It is of note that lto et al (2001) did not report such a stimulation in serumstarved mesangial cells, suggesting that fibrogenic cells with different phenotypes do not behave similarly in response to PDGF. We then tested whether PDGFinduced CTGF up-regulation was partly mediated by an intermediate TGF- $\beta 1$ production because we observed that PDGF stimulation was associated with a parallel 2-fold increase in TGF- $\beta 1$ mRNA expression. As expected, CTGF mRNA up-regulation was completely blocked by incubation with neutralizing antiTGF- $\beta 1$ antibody.

Finally, our study is the first to demonstrate the effect of CTGF on HSC migration and proliferation, two other key mechanisms associated with HSC activation. We show that CTGF also promotes migration of HSC, acting both by chemotaxis and chemokinesia. A significant effect of CTGF on HSC proliferation was also observed. It is of note that endogenous CTGF mRNA up-regulation occurs during spontaneous activation of HSC in standard culture conditions. To avoid as much as possible a masking effect of endogenous CTGF overproduction on rCTGF addition, we studied HSC in their quiescent stage ( 3 to 4 days after isolation). Our results are in accordance with other studies reporting stimulation of cell migration by CTGF or related peptides in other cell types such as endothelial cells, vascular smooth muscle cells, and fibroblasts (Babic et al, 1999; Fan et al, 2000). These results strongly support a role for CTGF not only in liver fibrogenesis but also in proliferation and migration of HSC, two other functions gained by HSC during the activation process. It is of note that very recently, a stimulatory role for CTGF in metalloprotease expression has been demonstrated in smooth muscle cells (Fan and Karnovsky, 2002). Metalloprotease expression is also gained by HSC during activation, allowing remodeling of its microenvironment (Eng and Friedman, 2000). Therefore CTGF might have a central role in HSC activation.

CTGF receptors as well as signaling are under intense investigation, and it has recently been demonstrated that the multiligand receptor, low-density lipoprotein receptor-related protein/alpha2-macroglobulin receptor, has been demonstrated as a receptor for CTGF that has a major role in mediating CTGF biology (Segarini et al, 2001).
Thus, our study extends both the function of CTGF and its mechanism of regulation during HSC activation. Because of the effect of CTGF not only on ECM production but also on migration and proliferation, CTGF should be considered as a crucial key factor involved in the course of liver fibrogenesis. It might therefore represent an interesting target in antifibrotic strategies.

\section{Materials and Methods}

\section{Source of Products}

TGF- $\beta 1$ and PDGF were purchased from R\&D (Abingdon, United Kingdom). Anti-CTGF antibody, produced in rabbits as previously described, was kindly provided by S. Huet (Glaxo Wellcome Smith Kline, Les Ulis, France) (Paradis et al, 1999). rCTGF was kindly provided by P. Segarini (Fibrogen, San Francisco, California).

\section{HSC Culture}

HSC were isolated from normal male Sprague-Dawley rats as previously described (Schäfer et al, 1987). Briefly, the liver was dispersed by perfusion with pronase and collagenase. The resulting nonparenchymal cell suspension was filtered through a nylon membrane, washed three times in Grey's balanced salt solution buffer containing $1.6 \mathrm{mM} \mathrm{Ca}^{2+}, 1.2 \mathrm{mM} \mathrm{Mg}^{2+}$, and DNase, and then centrifuged through two successive Nycodenz gradients (Sigma Chemical Company, St. Louis, Missouri) of 15 and 10\%, respectively. After each gradient, HSC were recovered from the interface between Nycodenz and medium containing $0.3 \%$ BSA, washed in DMEM, and plated in DMEM supplemented with $10 \%$ each of calf and horse serum, $2 \mathrm{~mm}$ L-glutamine, $10 \mathrm{~mm}$ HEPES buffer, and 10,000 Ul/ml penicillin/10,000 $\mu \mathrm{g} / \mathrm{ml}$ streptomycin on uncoated tissue plastic at a density of $13010^{3}$ cells $/ \mathrm{cm}^{2}$. Cultures were incubated at $37^{\circ} \mathrm{C}$ in a humidified atmosphere containing $95 \% \mathrm{O}_{2}, 5 \% \mathrm{CO}_{2}$, and the medium was changed every day. Cell purity was around $95 \%$, as assessed by conventional techniques.

HSC were grown on plastic supports in various conditions and harvested at different intervals. Unless otherwise specified, experiments were performed at Days 3 to 4 after plating. For each condition, three independent experiments were performed. All experiments were performed according to procedures approved by the ethical committee.

\section{Western Blot}

HSC lysate from cells was subjected to sodium dodecyl sulfate-polyacrylamide gel electrophoresis under reducing conditions on $10 \%$ acrylamide gels and transferred to nitrocellulose filters by electroblotting. The blot was incubated for 1 hour in Tween-PBS with $5 \%$ nonfat dry milk and incubated overnight at $4^{\circ} \mathrm{C}$ with the anti-CTGF antibody (1:1000) diluted in Tween-PBS with $1 \%$ nonfat dry milk. The blot was then washed six times (15 minutes each) with TweenPBS and incubated with rabbit IgG for 1 hour at room 
temperature (1:1000; Dako, Carpenteria, California). After washes with Tween-PBS, the immunoreactive bands were detected using the chemiluminescence reaction method.

\section{mRNA Quantification by Real-Time RT-PCR}

mRNAs were quantified by a real-time RT-PCR procedure. Quantitative real-time PCR was performed using the ABI PRISM 7700 Sequence Detection System (Perkin-Elmer Applied Biosystems, Foster City, California). The precise amount of total RNA added to each reaction (based on optical density) and its quality were checked by the quantification of an endogenous RNA control RPLPO mRNA (also known as 36B4) encoding human acidic ribosomal phosphoprotein PO. Each sample was then normalized on the basis of its RPLP0 content. The sequences of primers for RPLPO, CTGF, TGF- $\beta 1$, and type I collagen, designed using computer programs Oligo 4.0 (National Biosciences, Plymouth, Minnesota) and Primer Express (PerkinElmer Applied Biosystems), are given in Table 1.

Total RNA was extracted from HSC by using the acid-phenol guanidinium method. Reverse transcription of total RNA was performed in a final volume of 20 $\mu$ l containing $1 \times$ RT buffer ( $500 \mu \mathrm{M}$ each dNTP, $3 \mathrm{~mm}$ $\mathrm{MgCl}_{2}, 75 \mathrm{~mm} \mathrm{KCl}, 50 \mathrm{~mm}$ Tris- $\mathrm{HCl}, \mathrm{pH}$ 8.3), $10 \mathrm{U}$ of RNasin inhibitor (Promega, Madison, Wisconsin), 10 $\mathrm{mm}$ dithiothreitol, $50 \mathrm{U}$ of Superscript II Rnase $\mathrm{H}^{-}$ reverse transcriptase (Gibco BRL, Gaithersburg, Maryland), $1.5 \mu \mathrm{M}$ random hexamers (Pharmacia, Uppsala, Sweden), and $1 \mu \mathrm{g}$ of total RNA. Samples were incubated at $20^{\circ} \mathrm{C}$ for 10 minutes, $42^{\circ} \mathrm{C}$ for 30 minutes; reverse transcriptase was inactivated by heating at $99^{\circ} \mathrm{C}$ for 5 minutes and cooling at $5^{\circ} \mathrm{C}$ for 5 minutes. Amplification reactions were performed using a SYBR Green PCR Core reagent kit (PerkinElmer Applied Biosystems). Ten microliters of diluted RT samples were used for quantitative two-step PCR (a 10-minute step at $95^{\circ} \mathrm{C}$, followed by 50 cycles of 15 seconds at $95^{\circ} \mathrm{C}$ and 1 minute at $65^{\circ} \mathrm{C}$ ) in the presence of $200 \mathrm{~nm}$ specific forward and reverse primers, $5 \mathrm{mM} \mathrm{MgCl}_{2}, 50 \mathrm{mM} \mathrm{KCl}, 10 \mathrm{mM}$ Tris buffer (pH 8.3), $200 \mu \mathrm{M}$ dATP, dCTP, dGTP, and $400 \mu \mathrm{m}$

Table 1. Primer Sequences of CTGF, Type I Collagen, TGF- $\beta 1$, and RPLPO in the Rat

\begin{tabular}{|c|c|}
\hline \multicolumn{2}{|l|}{ CTGF } \\
\hline Upper & 5' ATCCCTGCGACCCACACAAG 3' \\
\hline Lower & 5' CAACTGCTTTGGAAGGACTCGC 3' \\
\hline \multicolumn{2}{|l|}{ TGF- $\beta 1$} \\
\hline Upper & 5' CGGACTACTACGCCAAAGAAGT 3' \\
\hline Lower & 5' TGGTTTTGTCATAGATTGCGTT 3' \\
\hline \multicolumn{2}{|c|}{ Type I collagen } \\
\hline Upper & 5' AtgtTCAgCTTTGTGGACCT $3^{\prime}$ \\
\hline Lower & 5' CAGCTGACTTCAGGGATGT 3' $^{\prime}$ \\
\hline \multicolumn{2}{|l|}{ RPLPO } \\
\hline Upper & 5' GGCGACCTGGAAGTCCAACT $3^{\prime}$ \\
\hline Lower & $5^{\prime}$ CCATCAGCACCACAGCCTTC $3^{\prime}$ \\
\hline
\end{tabular}

RPLPO, the gene encoding human acidic ribosomal phosphoprotein PO.
dUTP and 1.25 U of AmpliTaq Gold DNA polymerase (Perkin Elmer Applied Biosystems). Each sample was analyzed in duplicate.

\section{Cell Migration Assay}

Migration assays were performed in modified Boyden chambers. A cell culture insert was placed in the well of a 12-well tissue culture plate (Becton Dickinson, Le Pont de Claix, France). The insert had a $10-\mathrm{mm}^{2}$ uncoated, translucent membrane with $8-\mu \mathrm{m}$ pores at the bottom. Freshly isolated HSC ( $10^{5}$ cells) suspended in DMEM were added in the insert to adhere to the upper surface of the membrane. rCTGF (final concentrations $10,50,100$, and $1000 \mathrm{ng} / \mathrm{ml}$ ) was introduced at Day 4 after plating either in the upper or lower chamber of the wells. Wells containing medium alone were used as controls. After incubation for 16 hours, culture medium was removed and HSC adhering to the membrane were fixed by $100 \%$ methanol and stained with May Grünwald Giemsa. The numbers of HSC on the upper surface and those on the lower surface were counted in five randomly chosen microscopic fields at a magnification of $\times 400$ by changing the focus. The proportion of migrating cells (migration index [MI]) was calculated as follows: $\mathrm{MI}=$ [number of cells on the lower surface/number of cells on the upper and lower surfaces] $\times 100$. Experiments were repeated three times.

\section{Proliferation Assay}

The effect of rCTGF $(10,50$, and $100 \mathrm{ng} / \mathrm{ml})$ on the proliferative activity of HSC was determined by BrdU. HSC were incubated in the culture medium supplemented with BrdU-labeling medium for 1 hour at $37^{\circ} \mathrm{C}$. After three washes, cells were fixed in $70 \%$ ethanol for 30 minutes at $-20^{\circ} \mathrm{C}$. Cells were then incubated with the anti-BrdU working solution for 30 minutes at $37^{\circ} \mathrm{C}$, followed by incubation with antimouse-lg-alkaline phosphatase solution for $30 \mathrm{~min}$ utes at $37^{\circ} \mathrm{C}$. Cells were washed and covered with the color substrate solution for 30 minutes at room temperature. The numbers of BrdU-positive cells were counted in 10 randomly chosen fields at a magnification of $\times 400$. Counting was performed in three independent experiments.

\section{Acknowledgements}

The authors thank Dr. Stéphane Huet and Dr. A. C. De Gouville for providing reagents and for their fruitful discussions.

\section{References}

Babic AM, Chen C-C, and Lau LF (1999). Fisp12/mouse connective tissue growth factor mediates endothelial cell adhesion and migration through integrin $\alpha_{v \beta 3}$, promotes endothelial cell survival, and induces angiogenesis in vivo. Mol Cell Biol 19:2958-2966.

Bradham DM, Igarashi A, Potter RL, and Grotendorst GR (1991). Connective tissue growth factor: A cysteine-rich 
mitogen secreted by human vascular endothelial cells is related to the SRC-induced immediate early gene product CEF-10. J Cell Biol 114:1285-1294.

Eng FJ and Friedman SL (2000). Fibrogenesis I. New insights into hepatic stellate cell activation: The simple becomes complex. Am J Physiol Gastrointest Liver Physiol 279:G7G11.

Fan WH and Karnovsky MJ (In press, 2002). Increased MMP-2 expression in CTGF over-expression vascular smooth muscle cells. J Biol Chem.

Fan W-H, Pech M, and Karnovsky MJ (2000). Connective tissue growth factor (CTGF) stimulates vascular smooth muscle cell growth and migration in vitro. Eur $\mathrm{J}$ Cell Biol 79:915-923.

Frazier K, Williams S, Kothapalli D, Klapper H, and Grotendorst GR (1996). Stimulation of fibroblast cell growth, matrix production, and granulation tissue formation by connective tissue growth factor. J Invest Dermatol 107:404-411.

Friedman SL and Roll FJ (1987). Isolation and culture of hepatic lipocytes, Kupffer cells, and sinusoidal endothelial cells by density gradient centrifugation with Stractan. Anal Biochem 161:207-218.

Grotendorst GR, Okochi H, and Hayashi N (1996). A novel transforming growth factor beta response element controls the expression of the connective tissue growth factor gene. Cell Growth Differ 7:469-480.

Hong HH, Uzel MI, Duan C, Sheff MC, and Trackman PC (1999). Regulation of lysyl oxidase, collagen, and connective tissue growth factor by TGF-beta 1 and detection in human gingiva. Lab Invest 79:1655-1667.

Igarashi A, Nashiro K, Kikuchi K, Sato S, Ihn H, Fujimoto M, and Grotendorst GR (1996). Connective tissue growth factor gene expression in tissue sections from localized scleroderma, keloid, and other fibrotic/skin disorders. J Invest Dermatol 106:729-733.

Igarashi A, Okochi H, Bradham DM, and Grotendorst GR (1993). Regulation of connective tissue growth factor gene expression in human skin fibroblasts and during wound repair. Mol Biol Cell 4:637-645.

Ito Y, Aten J, Bende RJ, Oemar BS, Rabelink TJ, Weening JJ, and Goldscheding R (1998). Expression of connective tissue growth factor in human renal fibrosis. Kidney Int 53:853-861.

Ito $\mathrm{Y}$, Goldschmeding R, Bende RJ, Claessen N, Anwar Chand M, Kleij L, and Rabelink TJ (2001). Kinetics of connective tissue growth factor expression during experimental proliferative glomerulonephritis. J Am Soc Nephrol 12:472484.
Nakatsukasa H, Nagy P, Evarts RP, Hsia C, Marsden E, and Thorgeirsson SS (1990). Cellular distribution of transforming growth factor $\beta 1$ and procollagen type I, III and IV transcripts in carbon tetrachloride-induced rat liver fibrosis. J Clin Invest 85:1833-1843.

Oemar BS, Werner A, Garnier JM, Do DD, Godoy N, Nauck M, and Marz W (1997). Human connective tissue growth factor is expressed in advanced atherosclerotic lesions. Circulation 95:831-839.

Paradis V, Dargère D, Vidaud M, De Gouville AC, Huet S, Martinez V, Gauthier JM, and Vidaud M (1999). Expression of connective tissue growth factor in experimental and human liver fibrosis. Hepatology 30:968-976.

Pinzani M, Guesualdo L, Sabbath GM, and Abboud HE (1989). Effects of platelet-derived growth factor and other polypeptide mitogens on DNA synthesis and growth of cultured rat liver fat-storing cells. J Clin Invest 84:1786-1789.

Schäfer S, Zerbe O, and Gressner AM (1987). The synthesis of proteoglycans in fat-storing cells of rat liver. Hepatology $7: 680-687$.

Sedlaczek N, Jia J-D, Bauer M, Herbst H, Ruehl M, Hahn EG, and Schuppan D (2001). Proliferating bile duct epithelial cells are a major source of connective tissue growth factor in rat biliary fibrosis. Am J Pathol 158:1239-1244.

Segarini PR, Nesbitt JE, Li D, Hays LG, Yates JR 3rd, and Carmichael DF (2001). The low density lipoprotein receptorrelated protein/alpha2-macroglobulin receptor is a receptor for connective tissue growth factor. J Biol Chem 276:4065940667.

Soma $Y$ and Grotendorst GR (1989). TGF- $\beta$ stimulates primary human skin fibroblast DNA synthesis via an autocrine production of PDGF-related peptides. J Cell Physiol 140: 246-253.

Tamatani T, Kobayashi H, Tezuka K, Sakamoto S, Suzuki K, Nakanishi T, and Takigawa M (1998). Establishment of the enzyme-linked immunosorbent assay for connective tissue growth factor (CTGF) and its detection in the sera of biliary atresia. Biochem Biophys Res Commun 251:748-752.

Williams EJ, Gaca MD, Brigstock DR, Arthur MJ, and Benyon RC (2000). Increased expression of connective tissue growth factor in fibrotic human liver and in activated hepatic stellate cells. J Hepatol 32:754-761.

Weiner FR, Giambrone MA, Czaja MJ, Shah A, Annoni G, Takahashi S, and Eghbali M (1990). Ito cell gene expression and collagen regulation. Hepatology 11:111-117. 